\title{
Significance of Social Skills among Adolescents
}

\author{
Renu Bala*, Sheela Sangwan and Poonam Rani \\ Department of Human Development and Family Studies, CCS Haryana Agricultural \\ University, Hisar-125004, India \\ *Corresponding author
}

\section{Keywords}

Adolescents, Social skills, Self

awareness,

Empathy, Effective communication and Interpersonal relationship

Article Info

Accepted:

20 February 2019

Available Online:

10 March 2019

\section{A B S T R A C T}

Adolescence, a vital stage of growth and development, marks the period of transition from childhood to adulthood. It is characterized by rapid physiological changes and psychological maturation. The adolescents have the intellectual maturity to assess a situation, assess the various aspects of the situation, challenge the prescription of others, develop a repertoire of skills, make a choice of own and later come to a conclusion about the skill and its execution. Social skills are considered as most important life skills for social well being of individuals. The social risks are many; poor mental health, dropping out of school, low achievement and other school difficulties, poor employment history. Social skills education plays a very vital role to increase the awareness among the youth about all social problems and to alleviate social evils from the society. It involves a person's relationship with others and how that person communicates, interacts and socializes with other people. It helps the individual to improve the ability to take everything in the right sense and also improve their contributions to the society. The present study focuses on the importance of social skills education and the benefits of imparting social skill education in our curriculum i.e. self awareness, empathy, effective communication and interpersonal relationship in adolescents, as they are the important building blocks for a dynamic citizen, who can cope with future challenges and survive well.

\section{Introduction}

Better education is very necessary for all to go ahead in the life and get success. It develops confidence and helps building personality of a person. Our good or bad education decides that which type of person we would in the future. Good education gives many purposes to the life such as enhancement of the personal advancement, increase social status, increase social health, economical progress, success to the nation, set goals of life, make us aware towards many social issues and gives solutions to solve environmental problems and other related issues. Education develops the people's minds to a great level and helps in removing all the differences in the society. It makes us able to become a good learner and understand every aspect of life. It provides ability to understand all the human rights, social rights, duties and responsibilities towards country. Through life 
skill education one can move towards more positive and holistic approaches in order to educate the new generations and through them the future generations. Life skills include self awareness, empathy, effective communication and interpersonal relationship dimensions as a social skills

Self-awareness includes recognition of characters strengths and weaknesses, desires and dislikes. It begins when an individual becomes aware of being a separate entity. Empathy is the ability to imagine what life is like for another person, even in a situation that may not be familiar with. Effective communication enables to express, both verbally and non-verbally, in ways that are appropriate to cultures and situations. Interpersonal relationship skills help to relate in interaction with positive ways with the people.

These skills will help adolescents in coping difficulties they face in their personal, emotional and social development. Through these skills adolescents learn to communicate with their teachers, adults and peers.

The present study therefore is an attempt made to understand the adolescent's problems and guide them in acquisition of these skills. The intervention on social skills development is a good support system for adolescents at the community level.

The objectives are

To develop and impart an intervention programme on social skills.

To study the significance of intervention programme on social skills.

\section{Materials and Methods}

The present study was conducted purposively in two institutions i.e. Haryana State and
Delhi. 50 girls and 50 boys were selected on random basis from both the institutions. Hence, a total of 200 adolescents constituted the sample for the study to assess the existing social skills. The adolescents were further assigned to experimental (50) and control (50) group.

\section{Social skills education}

Social skill is a goal-oriented process, which starts with accurate perception of the social situation, then the skill to behave according to the social situation, and finally the skill to adjust one's own behaviour according to the changing social situation. Social skills have further divided into 4 dimensions:

Self-awareness- includes recognition of 'self', our character, our strengths and weaknesses, desires and dislikes. Developing self-awareness can help us to recognize when we are stressed or feel under pressure.

Empathy- it is the ability to imagine what life is like for another person. Empathy can help us to accept others, who may be very different from ourselves.

This can improve social interactions, especially, in situations of ethnic or cultural diversity. Empathy can also help to encourage nurturing behaviour towards people in need of care and assistance, or tolerance.

Effective communication- means that we are able to express ourselves, both verbally and non-verbally, in ways that are appropriate to our cultures and situations.

Interpersonal relationship skills- help us to relate in positive ways with the people we interact with. This may mean being able to make and keep friendly relationships, which can be of great importance to our mental and social well-being. 
Imparting 'social skills education' in classroom

Based on pretested data, an intervention programme was developed for social skills. The intervention programme included different activities for enhancing social skills among adolescents. Intervention programme was divided in six dimensions of social i.e. self awareness, empathy, effective communication, interpersonal relationship. Thus, the significance of social skills education and in the following section researcher has tried to attempt, how much the help of simple activities that can be implemented in classroom settings.

\section{Appreciating the good qualities}

Once a person recognizes his/her strengths, he/she is able to cultivate the strengths and positive qualities and also work towards improving or doing away with one's weaknesses. This activity helps students to recognize their positive qualities.

\section{Enhancing self-esteem}

This activity will acquaint students with different ways of overcoming low selfesteem.

Here are tips to improve your self-esteem. Study them carefully and answer the questions:

Love yourself: Take care of yourself. Remember that you are unique.

Do what you love: This would give you a good feeling.

Write down your good qualities: This would remind you of your strengths.

Develop a long and short term goal: This can keep you motivated.

Have a sense of humor: Learn to laugh at yourself.

Help others - both people and animals: This brings pure joy and satisfaction.
Drop your negative friends: Because they pull down your confidence.

Celebrate success: Celebration boosts self confidence and good feeling

\section{Games}

Patience is a powerful attribute that enables a person to remain firm under stress. Patience cannot be acquired overnight. This activity is like a game which tries one's patience. Have a pile of pencils or match sticks in the middle of the room either on the floor or on a table. Let each student pick up a pencil or match sticks without moving any of the others. Let him/her keep the pencil if no other pencil moves but they have to put the pencil back if any other pencil moves.

\section{Asking questions}

Asking questions is an important indicator of good listening. This activity will help the students to practice listening skills by asking the right questions.

\section{Group discussions}

This activity will make the students understand the importance of participating in group discussions.

\section{Puzzles}

Each one is special and everyone needs to feel so. Everyone is unique also. Even being unique, each one has an important and special part to play in the group one works with. This activity will help students understand that each one holds a unique position in a whole.

\section{Appreciating good behaviour}

This activity focuses on building good relationships among students by appreciating others. 


\section{Results and Discussion}

Impact of intervention programme on social skills among adolescents of Delhi and Haryana

Table portrays the impact of intervention package on experimental group adolescents of both institutions. During post- testing stage of experimental group, the mean scores of selfawareness (39.91), empathy (38.83), effective communication (38.70), interpersonal relationship (31.70) were comparatively better against mean scores obtained by experimental group during pre-testing were $36.69,32.88$,
33.85 and 29.01 respectively. And for total social skills mean score for post-testing were 149.14 and pre-testing were 132.44 . The table 1 further shows that there were significant differences in pre and post testing of experimental group adolescents, as the ' $t$ ' values were statistically proved to be significant for all the four dimensions of social and emotional skills i.e. for self awareness t-values was $19.76^{*}$, for empathy $\mathrm{t}$ -values was $18.37^{*}$, for effective communication t-values was $21.82 *$, for interpersonal relationship t-values was $16.42^{*}$ and for total social skills t-values was $36.27^{*}$.

Table.1 Impact of intervention programme on social and emotional skills among adolescents of Delhi and Haryana

\begin{tabular}{|c|c|c|c|c|c|c|c|c|}
\hline \multirow{3}{*}{$\begin{array}{c}\text { Social and } \\
\text { emotional skills }\end{array}$} & \multirow{2}{*}{\multicolumn{4}{|c|}{ Experimental group }} & \multicolumn{4}{|c|}{$n=200$} \\
\hline & & & & & & Contı & ol group & \\
\hline & $\begin{array}{c}\text { Pre- } \\
\text { testing }\end{array}$ & $\begin{array}{l}\text { Post- } \\
\text { testing }\end{array}$ & $\begin{array}{c}\text { Mean } \\
\text { differences }\end{array}$ & $\begin{array}{c}\text { 't' } \\
\text { values }\end{array}$ & $\begin{array}{l}\text { Pre- } \\
\text { testing }\end{array}$ & $\begin{array}{l}\text { Post- } \\
\text { testing }\end{array}$ & $\begin{array}{c}\text { Mean } \\
\text { differences }\end{array}$ & $\begin{array}{c}\text { 't' } \\
\text { values }\end{array}$ \\
\hline & $\begin{array}{l}\text { Mean } \\
\text { (S.D.) }\end{array}$ & $\begin{array}{l}\text { Mean } \\
\text { (S.D.) }\end{array}$ & & & $\begin{array}{l}\text { Mean } \\
\text { (S.D.) }\end{array}$ & $\begin{array}{l}\text { Mean } \\
\text { (S.D.) }\end{array}$ & & \\
\hline Self-awareness & $\begin{array}{l}36.69 \\
(4.94)\end{array}$ & $\begin{array}{l}39.91 \\
(4.22)\end{array}$ & 3.22 & $19.76^{*}$ & $\begin{array}{l}36.73 \\
(5.91)\end{array}$ & $\begin{array}{l}37.11 \\
(5.66)\end{array}$ & 0.32 & 0.46 \\
\hline Empathy & $\begin{array}{l}32.88 \\
(4.70)\end{array}$ & $\begin{array}{l}38.83 \\
(5.29)\end{array}$ & 5.95 & $18.37 *$ & $\begin{array}{l}32.91 \\
(4.61)\end{array}$ & $\begin{array}{l}33.61 \\
(5.53)\end{array}$ & 0.96 & 0.80 \\
\hline $\begin{array}{l}\text { Effective } \\
\text { communication }\end{array}$ & $\begin{array}{l}33.85 \\
(4.68)\end{array}$ & $\begin{array}{l}38.70 \\
(3.63)\end{array}$ & 4.85 & $21.82 *$ & $\begin{array}{l}32.26 \\
(5.62)\end{array}$ & $\begin{array}{l}34.13 \\
(4.32)\end{array}$ & 1.08 & 0.84 \\
\hline $\begin{array}{l}\text { Interpersonal } \\
\text { relationship }\end{array}$ & $\begin{array}{l}29.01 \\
(3.45)\end{array}$ & $\begin{array}{l}31.70 \\
(4.63)\end{array}$ & 2.69 & $16.42 *$ & $\begin{array}{l}29.23 \\
(5.42)\end{array}$ & $\begin{array}{l}29.61 \\
(5.69)\end{array}$ & 0.20 & 0.44 \\
\hline $\begin{array}{l}\text { Total social } \\
\text { skills }\end{array}$ & $\begin{array}{l}132.44 \\
(10.56)\end{array}$ & $\begin{array}{l}149.14 \\
(12.23)\end{array}$ & 16.7 & $36.27 *$ & $\begin{array}{l}132.12 \\
(8.36)\end{array}$ & $\begin{array}{l}134.46 \\
(8.75)\end{array}$ & 2.50 & 1.69 \\
\hline
\end{tabular}

*Significant at $5 \%$ level

The table further shows that there were no significant differences in pre and post testing of control group adolescents, as the ' $t$ ' values were statistically proved to be non-significant for all four dimensions of social skills.

In conclusion, intervention is act of imparting knowledge and training to individual to improve their existing knowledge, capacity and efficiency regarding any skill. Intervention need to be aimed at the specific needs of the child.
No two children share the same set of strengths in order to build on the specific areas in the need of development. As such, intervention needs to be viewed as a dynamic ever changing process. Although this may sound 
overwhelming, initially, it is important to remember that the process of finding successful interventions becomes easier with the time and as the child's learning approach, style, and abilities become more easily seen.

The findings showed that after implementing intervention, there were significant improvements in self awareness, empathy, effective communication and interpersonal relationships of adolescents of experimental group. Danish et al., (2004) suggested that life skills are learned through demonstration, modeling and practice. Thus, in contrast, the learning of life skills is not a natural process in human development. Taneja et al., (2002) observed that implementation of a daily structured, 90-minute play session in an Indian institution led to significant gains in psychosocial, cognitive, and motor development. Larson (2000) identified that the advantages of implementing after-school activities, which, by fostering motivation and intense concentration in adolescents, allow them to develop positive skills such as initiative and the ability to set and achieve goals. Chawla et al., (2009) concluded that intervention programme made a positive impact on self esteem of rural adolescent girls. Intervention in the form of lectures, discussion, distribution of resource material like educational package, folders on self esteem helped in achieving the high self esteem.

In the light of above discussion, it could be concluded that, social skills education has its importance and significance in overall development of students.

\section{References}

Bhat A. and Aminabhavi V. Home environment and psychosocial competence of adolescents. J. Psychology, 2011. 2: 57-63.

Chawla A., Mahal R. and Thind S. Nurturing self esteem in rural adolescence girls. Psycholinguistics Association of India. 2009. 39: 125-127.

Connor R. C. Suicidal behaviour as a cry of pain: Test of a psychological model. Archives of Suicide Research, 2003.7: 297-308.

Csoti M. Social Awareness Skills for Children. London, England: Jessica Kingsley Publishers.

Elksnin L. K. and Elksnin N. 2004. The socialemotional side of learning disabilities. Learning Disability Quarterly, 2001.27: 38.

Danish S. J., Taylor T., Hodge K. and Heke I. Enhancing youth development through sport. World Leisure Journal, 2004. 46: 3849

De Anda D., Baroni S., Boskin L., Buchwald L., Morgan J., Ow J., Gold J. S. and Weiss R. Stress, stressors and coping among high school students. Children and Youth Services Review, 2000.22: 441-463.

Larson R. Towards a psychology of positive youth development. American Psychologist, 2000.55: 170-183.

Nair M. K. C. Family life \& life skills education for adolescents: Trivandrum experience. Child Development. 2005.1: 68-70

Pearl R. Students with Learning Disabilities and their Companions. In Wong, B. Y. L. \& Donahue, M. L. (Eds.), The Social Dimensions of Learning Disabilities: Essays in Honor of Tanis Bryan. Mahwah, NJ: Lawrence Erlbaum Associates. 2002.

Taneja V., Sriram S., Beri R. S., Sreenivas V. Aggarwal R. and Kaur R. Not by bread alone: Impact of a structured 90-minute play session on development of children in an orphanage. Child: Care, Health and Development, 2002. 28: 95-100.

\section{How to cite this article:}

Renu Bala, Sheela Sangwan and Poonam Rani. 2019. Significance of Social Skills among Adolescents. Int.J.Curr.Microbiol.App.Sci. 8(03): 2470-2474. doi: https://doi.org/10.20546/ijcmas.2019.803.292 